\title{
The Cell Cycle of the Pseudostratified Ventricular Epithelium of the Embryonic Murine Cerebral Wall
}

\author{
T. Takahashi, ${ }^{1,2}$ R. S. Nowakowski, ${ }^{3}$ and V. S. Caviness, Jr. ${ }^{1}$ \\ ${ }^{1}$ Department of Neurology, Massachusetts General Hospital, Harvard Medical School, Boston, Massachusetts \\ 02114, '2Department of Pediatrics, Keio University School of Medicine, Tokyo 160, Japan, and ${ }^{3}$ Department of \\ Neuroscience and Cell Biology, UMDNJ-Robert Wood Johnson Medical School, Piscataway, New Jersey 08854
}

\begin{abstract}
Neurons destined for the cerebral neocortex are formed in the pseudostratified ventricular epithelium (PVE) lining the ventricular cavity of the developing cerebral wall. The present study, based upon cumulative S-phase labeling with bromodeoxyuridine, is an analysis of cell cycle parameters of the PVE. It is undertaken in the dorsomedial cerebral wall of mouse embryos from the eleventh to the seventeenth gestational day (E11-E17, day of conception = E0) corresponding to the complete period of neuronogenesis. The growth fraction (fraction of cells in the population which is proliferating) is virtually 1.0 from E11 through E16. The length of the cell cycle increases from 8.1 to $18.4 \mathrm{hr}$, which corresponds to a sequence of 11 integer cell cycles over the course of neuronal cytogenesis in mice. The increase in the length of the cell cycle is due essentially to a fourfold increase in the length of G1 phase which is the only phase of the cell cycle which varies systematically. Thus, the G1 phase is most likely to be the phase of the cell cycle which is modulated by extrinsically and intrinsically acting mechanisms involved in the regulation of neuronal cytogenesis.
\end{abstract}

[Key words: cell cycle, proliferation, neuronogenesis, mouse, cerebrum, ventricular zone, neocortex]

The neurons of the neocortex arise within a proliferative pseudostratified ventricular epithelium (PVE) which forms the lining of the ventricular cavities of the developing cerebral wall (His, 1889; Schaper, 1897; Sauer, 1935; Sauer and Walker, 1959; Fujita, 1963; Stensaas, 1967; Hinds and Ruffett, 1971; Sidman and Rakic, 1982; Takahashi et al., 1992, 1994). The period of neuronogenesis within this proliferative population is discrete in onset and termination (Sidman et al., 1959; Berry and Rogers, 1965; Rakic, 1974; Caviness, 1982; Bayer and Altman, 1991). Cells of glial lineage, by contrast, proliferate throughout a much wider zone of the subcortical cerebral wall (Takahashi et al., 1995) and through a much more extended interval which probably begins before and continues beyond the neuronogenetic ep-

\footnotetext{
Received Feb. 23, 1995; revised Apr. 26, 1995; accepted Apr. 27, 1995.

This work was suppuited by NIH Grants NS12005 and NS28061, NSF Giant BNS8921020, and a grant from NASA. T.T. was supported by a fellowship of The Medical Foundation, Inc., Charles A. King Trust, Boston, MA. We gratefully acknowledge valuable suggestions and other assistance of Pradeep Bhide, Sahoko Miyama, and Nancy Hayes.

Correspondence should be addressed to Takao Takahashi, Department of Neurology, Massachusetts General Hospital, 25 Fruit Street, Boston, MA 02114.

Copyright (C) 1995 Society for Neuroscience $0270-6474 / 95 / 156046-12 \$ 05.00 / 0$
}

och (Smart, 1961; Smart and Leblond, 1961; Boulder Committee, 1970; Palterson el al., 1973; Privat, 1975; Mares and Bruckner, 1978; LeVine and Goldman, 1988; Altman and Bayer, 1990; Levinson and Goldman, 1993).

The neuronal classes which arise within the PVE are unique in the CNS for their variety and their great numbers (Ramon $y$ Cajal, 1952; Lorente de No, 1938; Jones, 1984). The succession of cell classes formed in the cerebral PVE and the rate at which the specific classes are formed must reflect the combinatorial actions of a host of regulatory mechanisms acting both extrinsically and intrinsically to the cells of the proliferative population. The unfolding of the overall regulatory program will be reflected in the kinetics of the proliferative behavior of the cells of the epithelium. Characterization of the proliferative behavior in terms of its kinetics is viewed as an early step indispensable to later investigations into cell and molecular biological regulatory mechanisms themselves.

The present report is an analysis of the cell cycle kinetics of the PVE of the dorsomedial cerebral wall of the mouse. The scope of the study is the full sweep of the neocortical cytogenetic epoch, initiated at embryonic day 11 (E11) and terminated on early E17 (Sidman et al., 1959; Caviness and Sidman, 1973; Shoukimas and Hinds, 1978; Caviness, 1982). The analysis is based upon cumulative labeling with bromodeoxyuridine (BUdR) of nuclei of the PVE as they cycle through $S$ phase. An earlier report from these investigations considered the proliferative behavior of the PVE limited to E14 (Takahashi et al., 1992, 1993). It provided the general conceptual framework and a detailed presentation of methodology for the present more comprehensive analysis. In part this analysis retraces experiments in the rat of Waechter and Jaensch (Waechter and Jaensch, 1972; Schultz et al., 1974) executed two decades ago. The present initiative is justified, however, by substantial advances in technology which will increase both the sensitivity and the specificity of the observations themselves (Nowakowski et al., 1989). It is additionally justified by intervening advances in the cell and molecular biology of cell cycle regulation and the potential for their application to the study of neocortical histogenesis (Hunt, 1991; Matsushime et al., 1992; Richardson et al., 1993; Sherr, 1993; Tsai et al., 1993, 1994).

\section{Materials and Methods}

Animals. CD1 mice, used for these studies, were maintained on a $12 \mathrm{hr}$ (7:00 A.M. to 7:00 P.M.) light-dark schedule. Conception was ascertained by the presence of a vaginal plug with the day of conception considered to be E0. Plug-checks were conducted at 9:00 A.M.

$S$-Phase labeling with BUdR. A succession of BUdR injections administered intraperitoneally into the pregnant dam is initiated at 9:00 


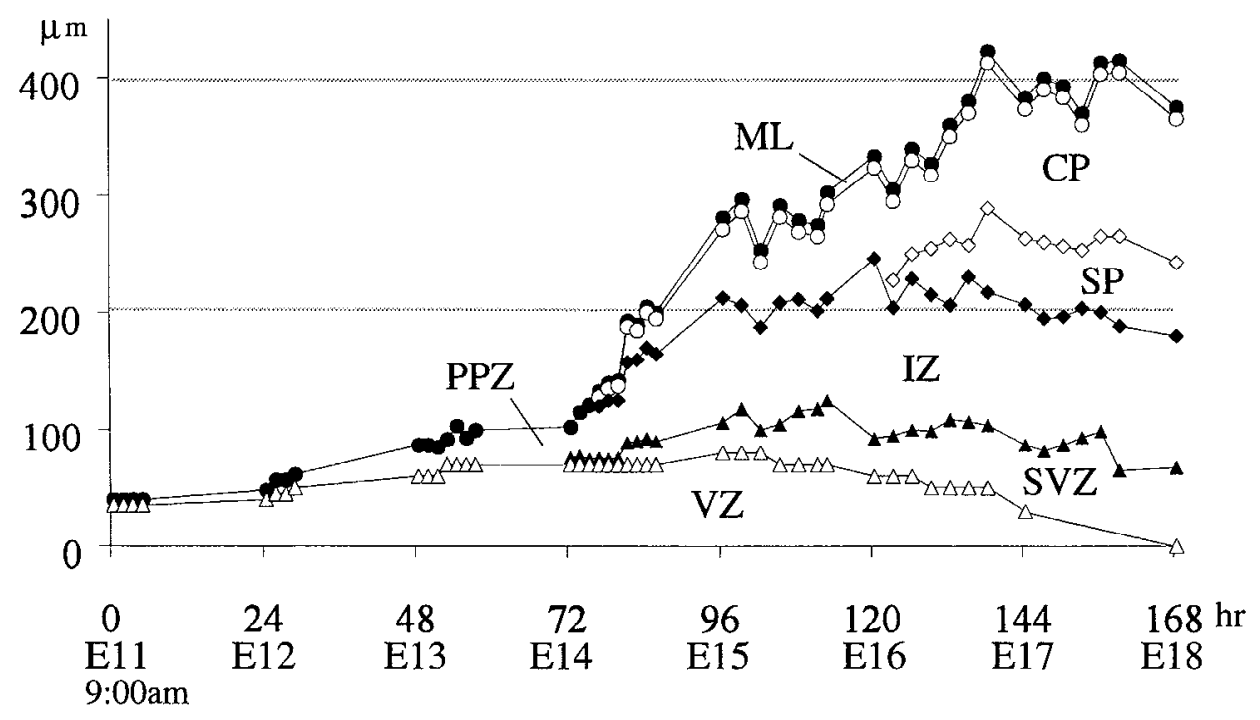

Figure 1. Cerebral stratification from E11-E18. The changing pattern of cerebral stratification throughout the full cytogenetic interval, E11-E18 where the abscissa represents this interval in terms of hours elapsed after 9:00 A.M on E11. At each time point, the averaged value for the upper border of each of the layers is plotted on the ordinate as the distance in micrometers from the ventricular surface. Until early E14 the cerebral wall has only two strata, the primitive plexiform zone $(P P Z)$ and the ventricular zone $(V Z, \triangle)$. The $V Z$ approaches its maximum width on E15 and then declines rapidly through E16. The cortical strata [molecular layer $(M L)$, cortical plate $(C P, O)$, and subplate $(S P, \diamond)]$ and the intermediate zone $(I Z, \downarrow)$, including the subventricular zone $(S V Z, \mathbf{\Lambda})$, by contrast progressively increase in width through E16. Pia.
A.M. on each of E11-E17. On each day the injections are repeated at $3 \mathrm{hr}$ intervals until the proportion of labeled nuclei (labeling index, LI) in the ventricular zone (VZ) is maximum (Takahashi et al., 1992, 1993). Survival times were spaced at $1.5 \mathrm{hr}$ intervals at E11-E14 and at 3.0 hr at E15-E17. On E18 BUdR was injected only once at 9:00 A.M. and the animals were sacrificed $30 \mathrm{~min}$ after the injection. The dose employed here, established previously to be effective in labeling $100 \%$ of cells in $\mathrm{S}$ phase, appears not to be cytotoxic over intervals corresponding to the duration of these experiments (Nowakowski et al., 1989; Takahashi et al., 1992).

Histology. Embryos were removed by hysterotomy from dams deeply anesthetized by an intraperitoneal injection of a mixture of ketamine $(50 \mathrm{mg} / \mathrm{kg}$ body weight) and xylazine $(10 \mathrm{mg} / \mathrm{kg}$ body weight). E $11-$ E14 embryos were decapitated, and the whole heads were fixed in 70\% ethanol. E15-E18 cmbryos were perfused via the left ventricle with $70 \%$ ethanol and the brains were dissected from the skull. The brains were postfixed overnight by immersion in $70 \%$ ethanol, dehydrated in graded ethanol solutions, embedded in paraffin, and sectioned at $4 \mu \mathrm{m}$ in the coronal plane. The sections were stained immunohistochemically for BUdR and counterstained with basic fuchsin as previously described (Takahashi et al., 1992, 1993).

Analysis. Analysis of the development of the hemispheric wall is undertaken in a standard coronal sector of the dorsomedial cerebral wall (Takahashi et al., 1992, 1993). The sector is $100 \mu \mathrm{m}$ in its mediallateral dimension and $4 \mu \mathrm{m}$ (corresponding to section thickness) in its rostral-caudal dimension. The sector is divided in its radial dimension into bins $10 \mu \mathrm{m}$ in height, and the bins are numbered $1,2,3$, and so on from the ventricular margin for purposes of mapping the location of cell nuclei (Takahashi ct al., 1992, 1993). The number of labeled and unlabeled cells were counted in each bin as previously described (Takahashi et al., 1992). An LI was calculated as the ratio of labeled to total cells (i.e., the sum of the number of labeled and unlabeled cells).

\section{Results}

The architectonically defined VZ (Boulder Committee, 1970) is approximately coextensive with the PVE (Takahashi et al., 1992, 1993). There is, however, not a perfect correspondence between the extent of the cells of the PVE and the borders of the VZ. Thus, a relatively small proportion of cells of the $\mathrm{VZ}$ are not part of the PVE. Some of these are postmitotic young neurons in the course of exit from the $\mathrm{VZ}$ and while others are proliferative cells of the secondary proliferative population (SPP, Takahashi et al., 1992, 1993, 1994, 1995). In addition, some cells of the PVE extend beyond the borders of the VZ into what is architectonically called the subventricular zone (SVZ, Takahashi et al., 1993, 1994, 1995). The height of the VZ on E11 at the outset of cortical neuronogenesis is about $40 \mu \mathrm{m}$ (Figs. 1, 2).
The height of this stratum increases to $70 \mu \mathrm{m}$ by E15 but declines precipitously through E16 and early E17. After the completion of neuronogenesis on $\mathrm{E} 17$, the $\mathrm{VZ}$ is replaced by the simple cuboidal ependymal lining of the ventricular cavity.

The cycle of expansion and regression of the VZ occurs concurrently with dramatic architectonic changes in the overlying cerebral wall (Figs. 1,2). Prior to E14, the VZ occupies most of the width of the cerebral wall with only the narrow primitive plexiform zone (PPZ) lying between this stratum and the pia. In the course of E14 the strata which constitute the cortical anlagen (molecular layer, cortical plate and subplate) and the subcortical intcrmediate zone and SVZ cmerge within the PPZ (Takahashi et al., 1993). The height of the collective cortical anlagen increases continuously through F.18 as that of the V7. regresses.

The number and distribution of the nuclei of cells in $S$ phase were estimated by "pulse labeling" with BUdR (Figs. 2, 3). The labeled nuclei are distributed to bins in the outer half of the VZ, referred to here as the "S-phase zone" of the VZ (Takahashi et al., 1992). The distribution profile of nuclei in $S$ phase (S-phase profile of the $\mathrm{VZ}$ ) during the interval E11-E18 illustrates the cycle of expansion and regression of the PVE in parallel with that of the VZ. The S-phase profile for each of days E11-E18, marked by a $30 \mathrm{~min}$ exposure to BUdR, is plotted in Figure 3. The labeled nuclei which will have progressed to $G 2$ phase during 30 min elapsed between injection of BUdR and animal sacrifice will have moved to the inner shoulder of the distribution of labeled nuclei (the shoulder closer to the ventricular surface or bin 1 as plotted in Figure 3, Takahashi et al., 1992, 1993).

The base of the outer shoulder of the S-phase profile for each day corresponds approximately to the boundary between $\mathrm{VZ}$ and overlying stratum, that is, the PPZ on E11-early E14 and the SVZ after E14. Over the E11-E13 interval cells in S phase pre dominate within the $\mathrm{VZ}$. The cells in $\mathrm{S}$ phase remain prominent through E15, but their proportion becomes diminished through E16 and early E17 as the neuronogenetic cycle is completed. A discrete $\mathrm{S}$ phase zone within the VZ is identified at the latest by the BUdR injection at 9:00 A.M. on E17. By early E18 proliferating cells of the SPP (Takahashi et al., 1995) are widely distributed from the ventricular surface to the overlying cerebral strata (Figs. 2, 3). The PVE has been replaced by the nonpro- 


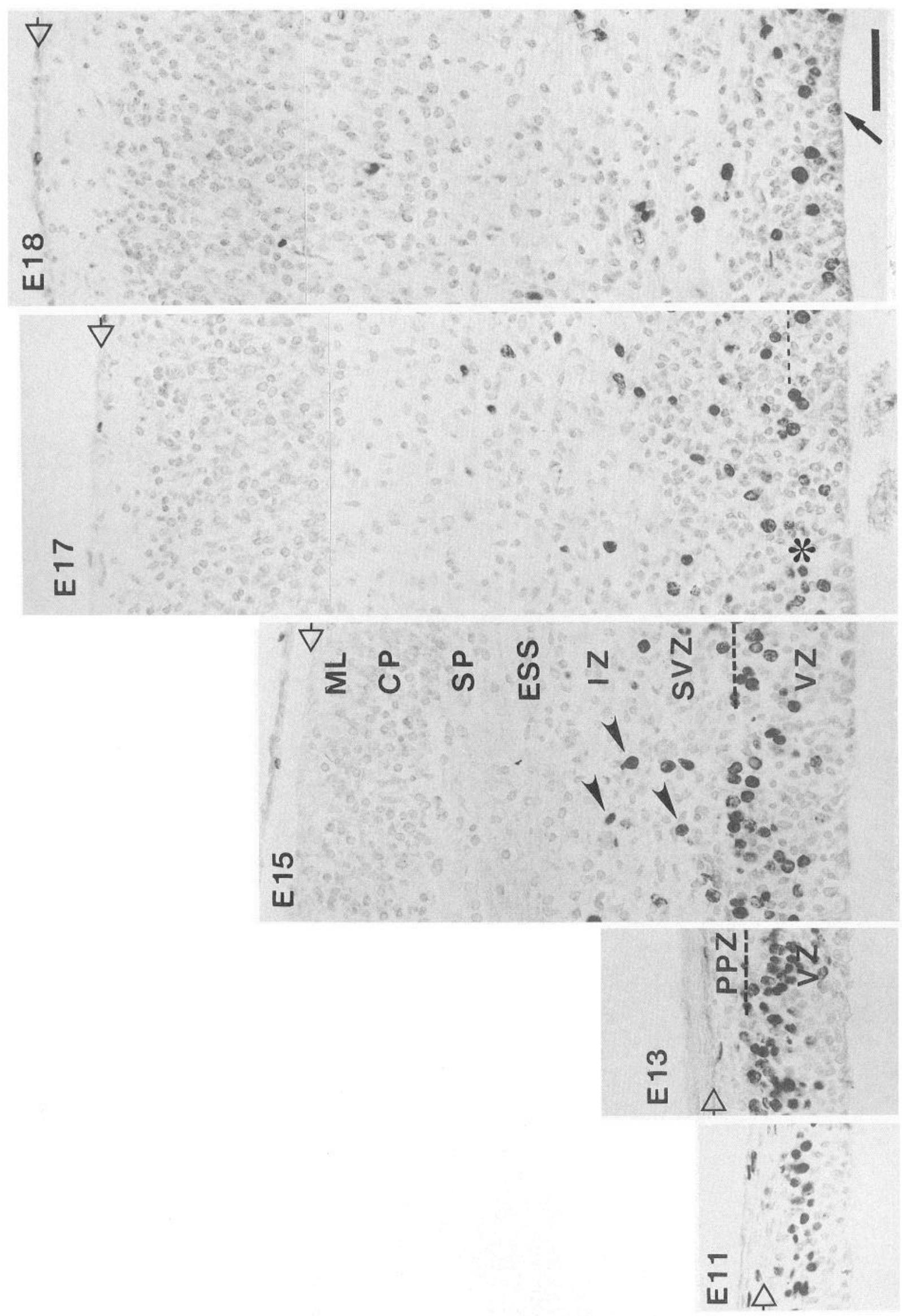


liferative cuboidal ependyma at the margin of the ventricular cavity.

\section{The growth fraction (GF) of the PVE}

The PVE, which can not be strictly delimited by architectonic criteria, is approximately coextensive with the $\mathrm{VZ}$, which can be delimited by architectonic criteria (Takahashi et al., 1992, 1993). For this reason the GF for the PVE is taken to correspond to the maximum LI achieved in the VZ. Cumulative exposure to BUdR over the first $2 \mathrm{hr}$ is associated with spread of the population of labeled nuclei from the $S$ phase zone, that is, the outer VZ, toward the ventricular margin (Fig. 4). The pattern of spread of labeled nuclei during the first $2 \mathrm{hr}$ of exposure to the tracer is essentially the same on each day of the E11-E17 interval. As cumulative exposure to BUdR continues for longer than $2 \mathrm{hr}$, the LI progressively increases throughout the full width of the VZ. The pattern of accumulation of labeled nuclei within the VZ differs principally in that accumulation develops more slowly on successive days of the E11-E16 interval (Fig. 4). The LI becomes 1.0 first in bin 1 and then in the bins successively distant from the ventricular margin including, finally, those bins corresponding to the S-phase zone itself. On days E11-E13 the LIs for the bins within the VZ ultimately become virtually 1.0 . That is, on E11-E 13 nearly $100 \%$ of nuclei are eventually labeled which indicates that GFs for the $\mathrm{VZ}$ are uniformly near 1.0. On E14 E16 the LIs for the bins in the outer margin of the $V Z$ reaches the maximum value which is less than 1.0 corresponding to a slight lowering of the GF of the VZ which is probably only apparent. It is likely that this apparent slight drop in the GF reflects the presence at the interface of VZ and SVZ of unlabeled nuclei of two different nonproliferative cell types: postmitotic young neurons which exited $S$ phase just before the initial injection of BUdR and nuclei of radial glial cells in G0 phase (Takahashi et al., 1993). Therefore, the actual GF of the PVE, although not of the entire VZ, probably holds constant at 1.0 through E16.

Proliferative activity of the PVE is essentially concluded on E17. An initial injection of BUdR at 9:00 A.M. does identify a distribution of $\mathrm{S}$ phase nuclei in the outer half of the much attenuated $\mathrm{VZ}$ (Figs. 2, 3A, 4B,C). Over the following $2 \mathrm{hr}$ the labeled nuclei progress toward the ventricular margin with the appearance of labeled mitotic figures just as in the E11-E16 interval. However, in contrast to the labeling patterns during these earlier days, the $L I$ in the $V Z$ reaches its maximum value which is much less than 1.0 as early as $9.5 \mathrm{hr}$ after the initial injection at 9:00 A.M. This is because, at this point, essentially all daughter cells belonging to the PVE are leaving the epithelium, most presumably, as migrating young neurons. Because cytogenesis in the PVE is concluded, the parameters of the cell cycle can not be estimated directly by cumulative labeling.

\section{Cell cycle parameters of the PVE}

The length of the cell cycle $\left(T_{C}\right)$ and $S$ phase $\left(T_{S}\right)$ of the PVE are estimated from the LIs for the PVE with cumulative exposure to BUdR beginning at 9:00 A.M. on E11-E16 (Figs. 4, 5; Takahashi et al., 1993). On E11-E13, the PVE and VZ are closely coextensive so that the architectonically delimited height of the $\mathrm{VZ}$ during these $3 \mathrm{~d}$ is taken to define the height of the proliferative PVE population in estimating the LI for the PVE.

On E14-E16, however, the height of the VZ is an underestimate of that of the PVE (Takahashi et al., 1993). This is because a fringe of nuclei belonging to the longest cells of the PVE extends into the SVZ above the architectonically evident outer margin of the VZ. These nuclei belong to cells which are in late G1 and early $\mathrm{S}$ phases. Computations of $T_{C}$ and $T_{S}$ must include these longest cells extending beyond the apparent limits of the VZ. Otherwise, the estimate of values for $T_{C}$ and $T_{S}$ would be shortened. In an earlier analysis limited to E14 (Takahashi et al., 1993), we made the adjustment of assigning to the PVE a full bin in height in excess of the apparent height of the $\mathrm{VZ}$, and this adjustment is observed here for the later days (see Fig. 5 caption for detail). Computations of $T_{C}$ and $T_{S}$ were not undertaken directly on E17 but were estimated indirectly by extrapolation from the patterns of progression of values on the earlier days.

The LIs for the set of bins corresponding to the PVE determined as described above for each of the days E11-E16 form a family of approximately linear curves (Fig. 5). $T_{C}-T_{S}$ corresponds to the cumulative labeling time required to achieve the maximum LI (Nowakowski et al., 1989; Takahashi et al., 1993). $T_{S} / T_{C}$ corresponds to the LI where the slope is extrapolated to the y-axis (Takahashi et al., 1993). For each date E11-E16, the two equations are solved simultaneously to give the corresponding values for $T_{S}$ and $T_{C}$. The length of $\mathrm{G} 2$ phase $\left(T_{G 2}\right)$ corresponding to the labeling time required to label the first mitotic figures at the ventricular margin was invariant at $1 \mathrm{hr}$ for each of the days E11-E16. The combined length of G2 and M phases ( $T_{G 2+M}$ ) corresponding to the cumulative labeling time required to label all mitotic figures at the ventricular margin, had an identical value of $2.0 \mathrm{hr}$. The values for the lengths of $\mathrm{Gl}$ phase $\left(T_{G 1}\right)$ for each day are obtained as $T_{C}-\left(T_{S}+T_{G 2+M}\right)$.

The value for $T_{C}$ increases from 8.1 to $18.4 \mathrm{hr}$ between E11 and E16 (Table 1, Fig. 6). The values for $T_{S}$ varies unsystematically at around $4 \mathrm{hr}$ through the interval E1 $1-E 16$. As described above, $T_{G 2+M}$ is invariant at $2 \mathrm{hr}$. In contrast to the values of $T_{S}$

Figure 2. The dorsomedial region of the murine cerebral wall at E11,13,15, 17, and 18. Photomicrographs of coronal $4 \mu \mathrm{m}$ sections stained immunohistochemically for BUdR and weakly counterstained with basic fuchsin. BUdR was given by intraperitoneal injection into the pregnant dam $0.5 \mathrm{hr}$ before the embryos were removed by hysterotomy. The distribution of the labeled nuclei (stained black) corresponds to the distribution of nuclei in $\mathrm{S}$ phase. Labeled cells are concentrated at high density in the outer half of the ventricular zone ( $V Z$ ) corresponding to the $\mathrm{S}$ phase zone of the VZ. By E15 the strata of the developing cortex ( $M L$, molecular layer; $C P$, cortical plate; $S P$, subplate) have emerged and the cortex is delimited from the underlying intermediate zone $(I Z)$ by the external sagittal stratum (ESS). The subventricular zone (SVZ) can be distinguished in the depths of the IZ, at its interface with the VZ. At E15 the S phase zone of the PVE is prominent in the outer half of the VZ. Labeled cells representing distribution of cells in S phase of the secondary proliferative population $(S P P)$ are distributed through the SVZ and overlying regions of IZ (arrowheads). Through E17-E18 there is an additional modest increase in the width of the IZ and cortical strata but a sharp decline in that of the VZ which is replaced by the simple cuboidal ependyma at the margin of the ventricle by E18. At 9:30 A.M. on E17, there is only a vestige of an S-phase zone in the VZ (*). The population of S-phase cells of the SPP, by contrast, has increased, and there are S-phase cells within the cuboidal ependyma at E18 (an arrow). Scale bar in E18, $50 \mu \mathrm{m}$ for E11-E18. PPZ, primitive plexiform zone. Open arrowheads, Pia. Broken lines, VZ-SVZ border. 
A
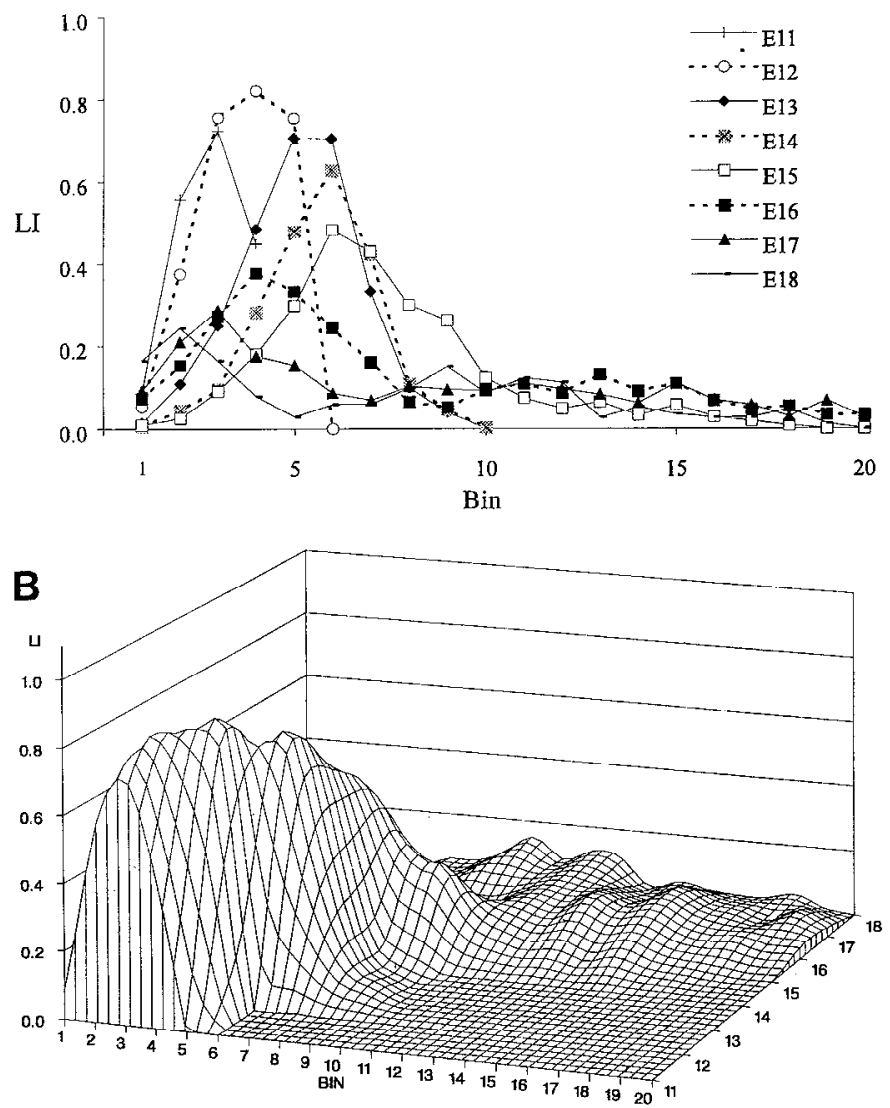

Figure 3. Two-dimensional $(A)$ and three-dimensional $(B)$ plots of labeling indices $(L I)$ after a single exposure to BUdR. The animals are sacrificed at each of the days E11-E18, 30 min following a single exposure to BUdR. A, Two-dimensional representation of the LI plotted as a function of depth in the cerebral wall. By convention the cerebral wall is divided into bins $10 \mu \mathrm{m}$ in height from the ventricular surface outward. The distribution of labeled nuclei approximates the distribution of nuclei in $S$ phase. These are most concentrated in the outer half of the ventricular zone at all ages, corresponding to cells in $\mathrm{S}$ phase in the PVE. Cells in $S$ phase at lower density throughout the overlying cerebral wall represent the secondary proliferative population. Within the PVE, the S-phase zone shifts outward from E11 to a maximum distance from the ventricular surface at E15 and then shifts back toward the ventricular surface on E16. This movement of the $S$ phase zone reflects the progressive increase followed by decrease in the width of the PVE over this interval. The SEM is less than $10 \%$ of the mean LI $(n=6)$ where the LI is greater than 0.1. For bins with LI of less than 0.1 the SEM is less than $0.01 . B$, Three-dimensional representation of the LI (z-axis) plotted as a function of bins (x-axis) and embryonic days ( $\mathrm{y}$ axis). As in $A$, the dominant representation at the time of the initial BUdR injection at each age is the cells in $S$ phase, with the nuclei in $S$ phase distributed in the outer half of the VZ ( $\mathrm{z}-\mathrm{x}$ plane). With this plot one visualizes in a single image the progressive outward expansion and then inward contraction of the PVE as reflected in the shift in the S-phase zone over the interval

and $T_{G 2+M}, T_{G l}$ increases fourfold between El l-E 16 from $3.2 \mathrm{hr}$ to $12.4 \mathrm{hr}$.

\section{Discussion}

The values for cell cycle parameters for the embryonic cerebral wall of the mouse, obtained here with the method of cumulative labeling with BUdR, accord closely with those of prior determinations in the rodent cerebrum. Thus, the present and prior studies indicate that $T_{C}$ increases as development proceeds in the rodent cerebral wall. An analysis in the rat, based upon cumulative labeling with ${ }^{3} \mathrm{H}$-thymidine $\left({ }^{3} \mathrm{H}\right.$-TdR, Waechter and Jaensch, 1972) found that $T_{C}$ increased from 11 to $19 \mathrm{hr}$ over the full cytogenetic epoch extending from E12-E19. As in the present analysis, the principal determinant of the increase in $T_{C}$ was an increasing $T_{G I}$. Other estimates following the onset of neuronogenesis have been $11 \mathrm{hr}$ at E11 (Atlas and Bond, 1965) and $15 \mathrm{hr}$ at E13 (Hoshino ct al., 1973). Values of $T_{C}$ for the PVE of the neural tube of the mouse at ages earlier than the onset of cerebral neuronogenesis have been as low as $8.5 \mathrm{hr}$ (Kauffman, 1966) and $8.0 \mathrm{hr}$ (Hoshino et al., 1973). Values for $T_{G 2+M}$, though somewhat more variable, have also been of a range of durations similar to the values obtain here (Atlas and Bond, 1965; Kauffman, 1966; Shimada and Langman, 1970; Waechter and Jaensch, 1972; Hoshino el al., 1973).

\section{Cell cycle evolution seen as a continuous progression}

The values for the cell cycle parameters for E11-E16, obtained experimentally, represent average values taken stepwise from a limited time of sampling for each of the respective days. $T_{C}-$ $T_{S}$, the experimental interval for each day, lengthens between E11 and E16. Thus, the time of sampling represents a progressively larger fraction of the respective embryonic day with progression from E11-E16. These values provide a stepwise view of change in cycle kinetics (Fig. 6).

Here we characterize progression of $T_{C}$ as one of continuous change, continuing through $6(24 \mathrm{hr}) \mathrm{d}$, or a total of $144 \mathrm{hr}$, beginning with the initial BUdR injection at 9:00 A.M. on E11 and continuing through 9:00 A.M. on E17 (Fig. 7A). We have computed separate regressions for the assumptions of linear $\left(T_{C}(t)=8.315+1.98 * / 24\right)$ and sigmoidal $\left(T_{C}(t)=8.567+\right.$ $\left.12.125(t / 24)^{2.615} / 15.380(t / 24)^{2.615}\right)$ progression of $T_{C}$. The two interpretations indicated that a total of 11 integer cycles will be executed by the lineages initiated at 9:00 A.M. on E11 and continuing through the termination of neuronogenesis on E17.

We plot as functions of hours elapsed from 9:00 A.M. on E11 the rate of traverse of the cytogenetic period in cycles/hr (Fig. $7 B$ ). With the sigmoidal to a somewhat greater degree than with the linear regression fit, these plots illustrate the progressive decline in the velocity of cycling with integer cycle progression from early to late in the cytogenetic interval.

As would be expected from the advance in $T_{C}$ (Fig. 7A) and reciprocal decline in cycle velocity (Fig. $7 B$ ) with cytogenetic time, well over half of the cycles have been traversed well before the half-way mark in the neuronogenetic period (Fig. $7 C$ ). Thus, 6 of the total 11 integer cycles are traversed at about the midpoint of the 3rd of the 6 total $24 \mathrm{hr}$ periods of cytogenesis. This corresponds to E13; neurons destined for the relatively cellsparse infragranular layers are being generated. The remaining five integer cycles are completed in the remaining 3.5 of the 24 hr periods to be completed. The majority of neurons destined for the densely cellular granular and supragranular layers are generated after E13 (Caviness, 1982), that is, in the course of execution of these final "sluggishly" proceeding cell cycles.

The neuronogenetic interval viewed as a succession of 11 integer cell cycles is a fundamental revision of perspective from the classic view based upon neuronogenetic days, for example E11-E17 for the mouse neocortex. The E11-E17 perspective does, of course, localize the proliferative process in developmental time. However, it carries no information about the proliferative process itself. With the perspective based upon integer cycle, by contrast, one comes directly to two parameters which 
$\mathbf{A}$

E11

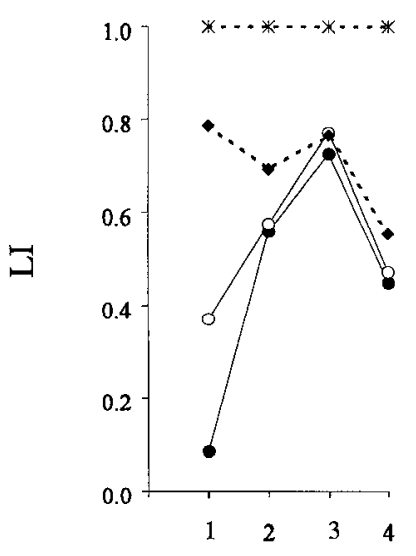

E12

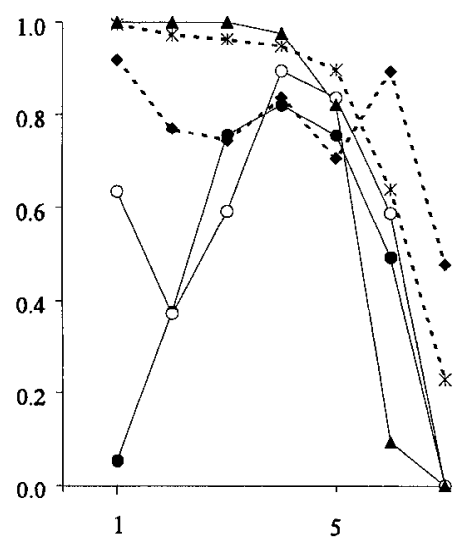

E13

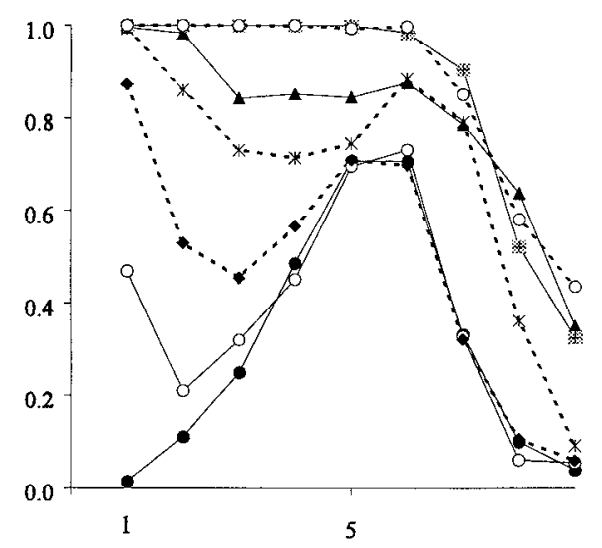

E14

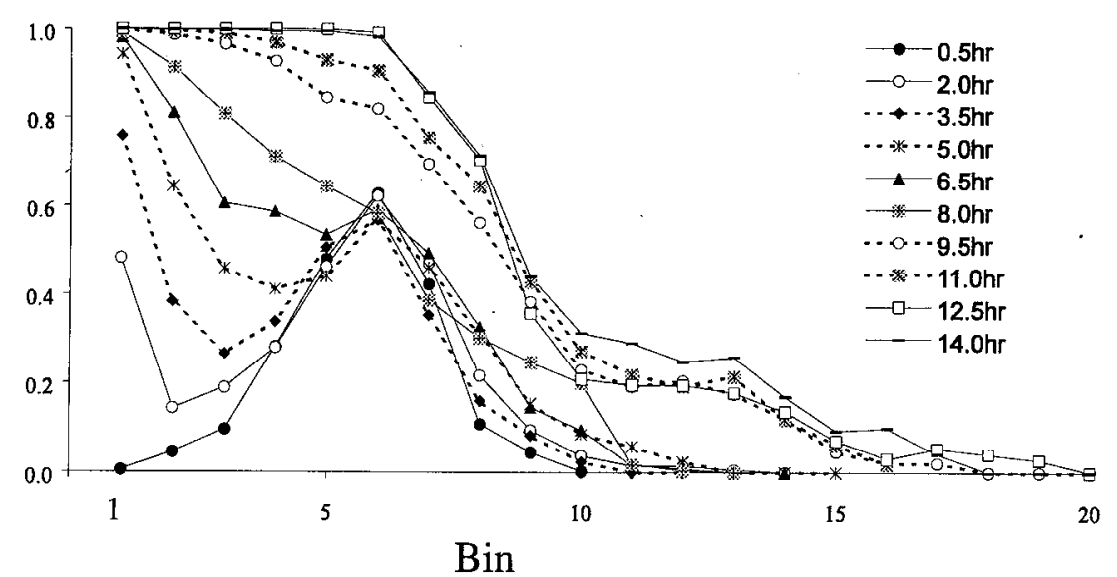

Figure 4. Two-dimensional $(A, B)$ and three-dimensional $(C)$ plots of labeling indices $(L I)$ with cumulative BUdR labeling. $A$ and $B$, The succession of labeling stages is represented by curves which indicate a progressive saturation of the proliferative population in the ventricular zone ( $V Z)$. This advances from the S-phase zone, illustrated after single injections in Figure 3, toward the ventricular surface and then through the intervening depth. With progression from early to late in neuronogenesis the S-phase zone becomes a smaller proportion of the total area of the VZ and proliferative activity of the PVE is essentially terminated with the plot at E17. The SEM is less than 10\% of the mean LI ( $n=6)$ where the LI is greater than 0.1 . For bins with LI of less than 0.1 the SEM is less than 0.01 . The legend in $A$ applies to the graphs for E11-E14 and that in $B$ to the graphs for E15-E17. C, The temporal sequence with cumulative labeling is expanded graphically along a third time axis. The LI ( $z$-axis) is plotted as a function of bins (x-axis) and time elapsed in hours (y-axis). With repeated injections of BUdR through E16, there is augmentation of the LI, with expansion of the distribution of labeled nuclei, first toward the ventricular margin ( $z$-y plane) then radially outward again through the $\mathrm{VZ}$ and into the subventricular and intermediate zones. On EII-E 13, the LI within the PVE reaches 1.0 (growth fraction $=1.0$ ) in a time corresponding to $T_{C}-T_{S}$. With progression from E11 to E16, there is decrease in the S-phase population relative to the total cell population of the PVE and increase in time required to label the whole proliferative population, that is, the length of $T_{C}-T_{S}$. The labeled population of the intermediate zone, lying above the VZ, becomes progressively more prominent (arrowheads). This represents the secondary proliferative population and postmitotic migrating neurons. At E17, the S-phase population of the PVE is greatly reduced $\left({ }^{*}\right)$. The entire PVE is contracting after E14 while the labeled cell populations of the cerebral wall overlying the PVE are expanding.

are the elementary determinants of neuronal cytogenesis. This is readily visualized when the values of $T_{C}$ and $T_{G I}$ are plotted as functions of both elapsed time and integer cycle (Fig. 8). Where the abscissa is time (Fig. $8 \mathrm{~A}$ ), the progression of values of $T_{C}$ and $T_{G I}$ are seen as related to time and are, hence, abstracted from the proliferative process and its pattern of cell production. Where the abscissa is integer cycle (Fig. 8B), hy contrast, it is the proliferative process itself that is salient. It is reasonable to expect that the total number of integer cycles will be a determinant of the total number of neurons to be generated over the total cytogenetic interval. This is because the integer cell cycle is the natural or biological denominator for the rate of cell production, and the total number of cells formed will be the sum of those produced with each of the integer cycles.

Whereas the progression through the series of integer cycles shows a clear increase in the values of $T_{C}$ and $T_{G /}$ over the period of neuronogenesis, the nature of this increase indicates that the values of $T_{C}$ and $T_{\sigma}$ are not determined directly by a clocklike, linear working of the cycling mechanism. Thus, the plots for $T_{C}$ and $T_{G \prime}$ as functions of integer cycle are nonlinear with relatively steep upward inclinations, in parallel, between the third and the sixth cycles (Fig. 8B). Said differently, the rate of advance in 


\section{B}
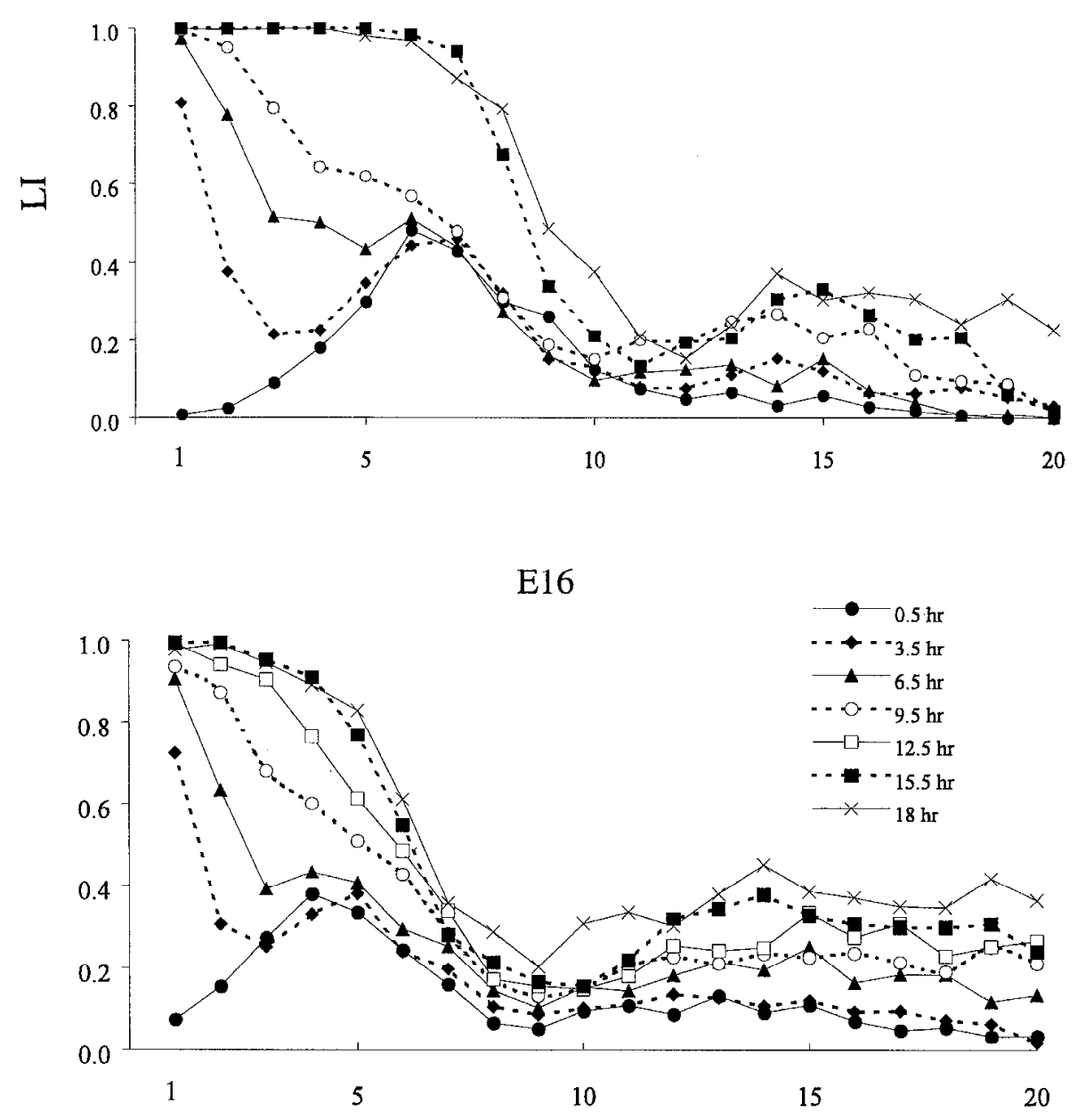

E17

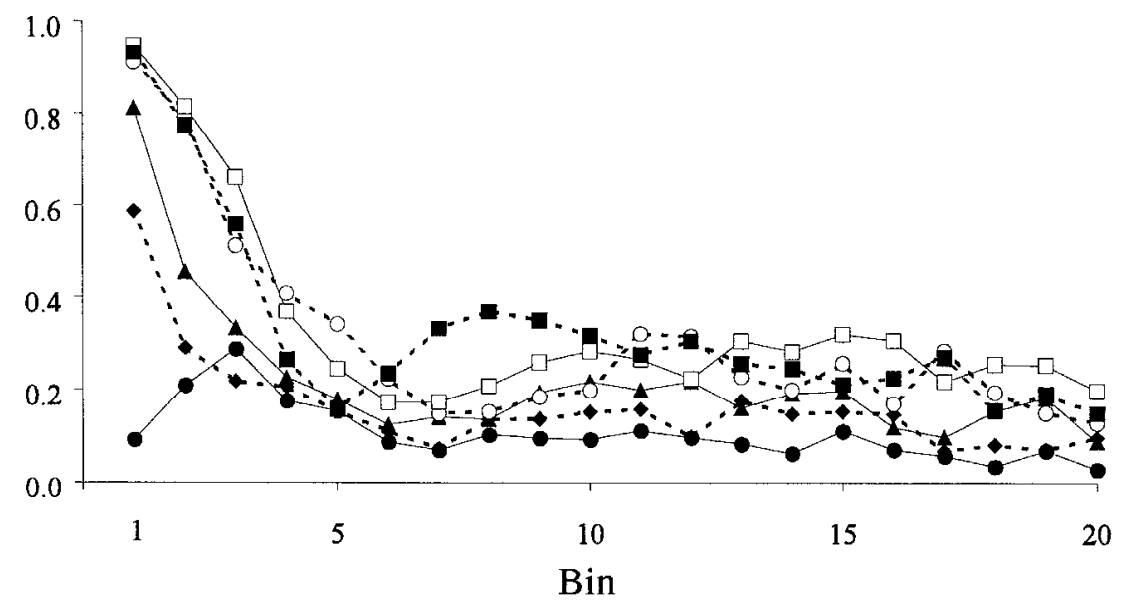

Figure 4. Continued.

these cytokinetic parameters is nonequivalent for each cycle through the succession of cycles. This implies that other determinants not counted by a "cycle number clock" are driving the cycle process with rapidly accelerating effect between the third and the sixth cycles. These determinants may be cell-external and fundamental to regulation of the overall cytogenetic phase of cerebral histogenesis (Caviness et al., 1994).

We also emphasize here that a characterization of the neuronogenetic interval in terms of the progression of integer cycles, is still not sufficient to serve as a model which predicts the total 

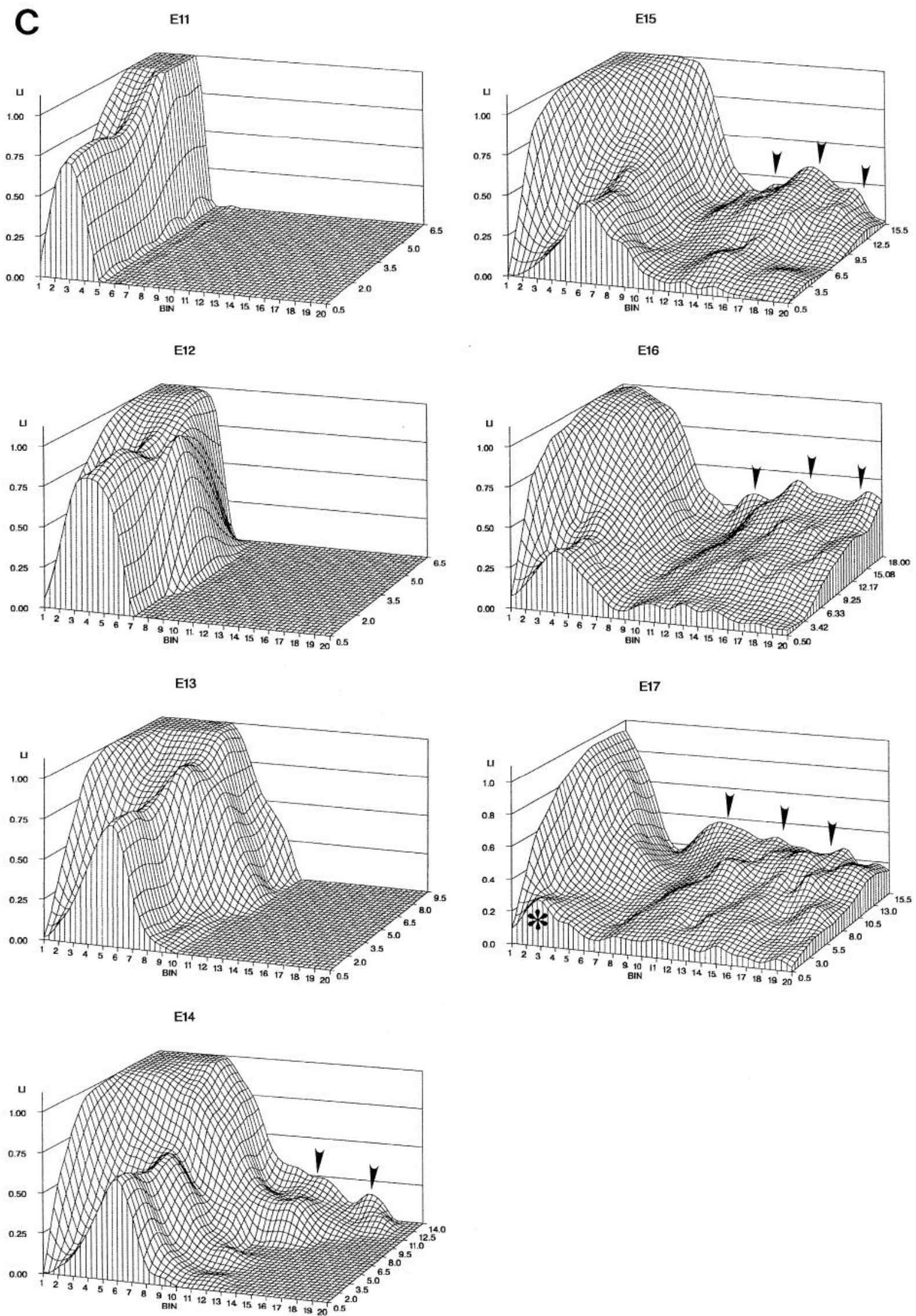

Figure 4. Continued. 


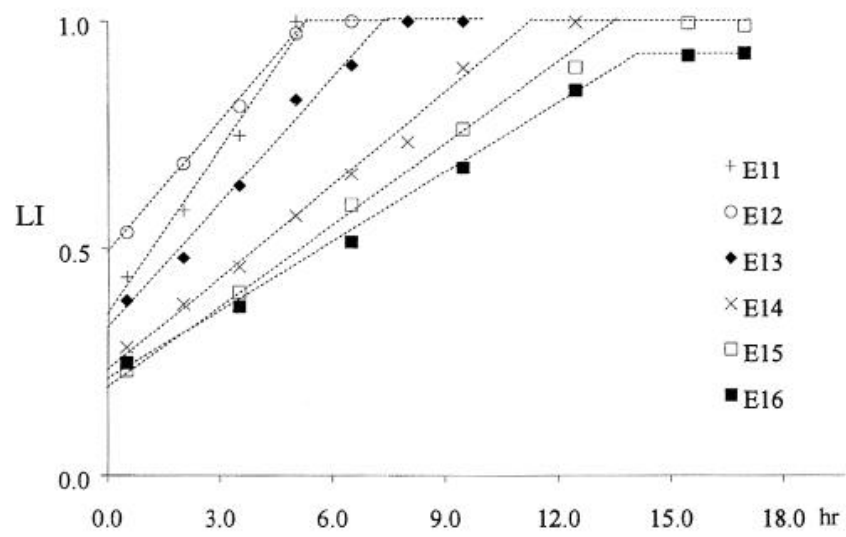

Figure 5. The progression of the LI of the PVE with cumulative labeling with BUdR. Cumulative exposure to BUdR was initiated at 9:00 A.M. on each of the days E11-E16. With each plot, the maximum LI provides an estimate of the growth fraction. The time at which the maximum LI is reached is equal to the length of the cell cycle minus the length of $\mathrm{S}$ phase $\left(T_{C}-T_{S}\right)$, and the y-intercept is equal to $T_{S} / T_{C}$. On E14-E16, the height of the VZ is an underestimate of that of the PVE. Thus, on E14 the height of the PVE was taken to be 7 bins when that of the VZ was 6 bins. On early E15, when the height of the VZ was maximum at 7 bins, the PVE was taken to be 8 bins in height. Later on E15 through E16, the height of the VZ declines. Late on E15, the height of the PVE was taken to be 7-6 bins (VZ 6-5 bins), early on E16 the height of the PVE was taken to be 6 bins and late on E16 this value was 5 bins. Although the slope of LI progression was obtained by a least squares fit considering all of the data for each of the time points (Takahashi et al., 1993), only the mean values are shown here for simple presentation's sake. The SEM is less than $10 \%$ of the mean value $(n=6)$ for all of the time points.

number of neurons which will be produced and the rate at which they will be produced. It must incorporate the fractional output parameter, $Q$ (the quiescent or quitting fraction, the fraction of cells which leaves the cycle at any moment, Takahashi et al., 1994), as $Q$ progresses through the succession of cell cycles. We have preliminarily considered the behavior of $Q$ over a part of the neuronogenetic interval in the dorsomedial PVE (Caviness et al., 1994). The estimated total output through the complete series of 11 cycles is estimated to correspond to something less than $10^{6}$ cells under a $1 \mathrm{~mm}^{2}$ surface area of the mature dorsomedial cortex. Given that the rate of programmed cell death may be at least as high as $50 \%$, this estimate is within an order of magnitude of the known value of $10^{5}$ (Schuz and Palm, 1989). Completion of the analysis of the behavior of $Q$ fraction throughout the 11 cycle sequence will enable a full model of the neuronogenetic process for the dorsomedial murine neocortex (Takahashi et al., unpublished observations).

\section{Regulation of $\mathrm{T}_{\mathrm{G} 1}$ and implications for neuronogenesis}

The PVE, as with proliferative populations elsewhere in the developing organism, has two principal agenda: the creation of cellular diversity and the production of the organ-appropriate total numbers of cells and at an appropriately regulated rate (Potten and Lajtha, 1982; Hall and Watt, 1989; Potten and Loeffler, 1990). Might the progressive lengthening of $T_{G l}$ be regulatory for these two agenda as they advance in the PVE? The cell population arising from the PVE will include diverse cell lineages. Thus, the population formed at any moment includes multiple projection and interneuronal classes and the profile of projection neuronal subclasses, at least, changes continuously through the course of cytogenesis (Rakic, 1974; Caviness, 1982;
Table 1. Summary of PVE cell cycle phase durations (hr) E11E16

\begin{tabular}{lrlll} 
& $T_{c}$ & $T_{s}$ & $T_{G 2+M}$ & $T_{G l}$ \\
\hline E11 & 8.1 & 2.8 & 2.0 & 3.2 \\
E12 & 10.2 & 4.9 & 2.0 & 3.3 \\
E13 & 11.4 & 3.9 & 2.0 & 5.5 \\
E14 & 15.1 & 3.8 & 2.0 & 9.3 \\
E15 & 17.5 & 3.7 & 2.0 & 11.8 \\
E16 & 18.4 & 4.0 & 2.0 & 12.4 \\
\hline
\end{tabular}

Miller, 1986; Mione et al., 1994). In general, with respect to laminar position, the neurons are formed in an "inside-out" sequence. Thus, the majority of polymorphic neurons of layer VI will arise before the majority of large pyramidal neurons of layer $\mathrm{V}$, and these before the medium sized and smaller pyramidal neurons of layers III and II. However, the neurons of two to three adjacent layers are in general formed concurrently (Sidman et al., 1959; Berry and Rogers, 1965; Hicks and D'Amato, 1968; Sidman and Rakic, 1973; Fernandez and Bravo, 1974; Rakic, 1974; Bisconte and Marty, 1975; Caviness, 1982; Luskin and Shatz, 1985; Bayer and Altman, 1991) so that even in larger gyrencephalic mammals the inside-out sequence of cortical neuron classes and subclasses are not formed in rigorous succession. Concurrently with neuronogenesis, radial glial cells, cells of the astroglial lineage, are also proliferating within the PVE (Levitt et al., 1981; Misson et al., 1988, 1991).

From these observations we arrive at two principal inferences relating neuronogenesis of multiple cell lineages in the PVE to the kinetics of the proliferative behavior. First, for the progenitors of cells of the same lineage but dividing at different times during the neuronogenetic period, $T_{C}$ and $T_{G /}$ will be different and the degree of difference will be a direct consequence of the interval (and number of integer cell cycles) separating the two divisions. This means that $T_{C}$ is not specific to a restricted lineage of cells. Second, for the aggregate population of the PVE dividing at an given moment and representing the progenitors

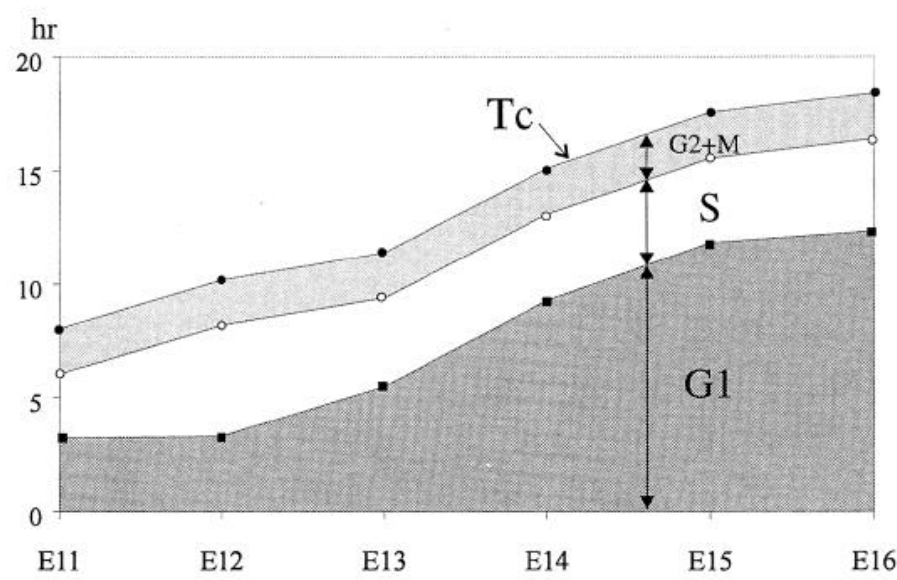

Figure 6. The progression in the lengths of the cell cycle phases of the PVE. The values for lengths of the cell cycle phases (Table 1) for each embryonic date E11-E16 are plotted as though the estimate is applied to the cell cycle initiated at 9:00 A.M. on the respective day. The length of overall cell cycle $\left(T_{C}\right)$ is approximately doubled over the interval E11-E16 with this increase due to increase in the length of G1 phase. There is no systematic change in either the length of $S$ phase or combined $\mathrm{G} 2$ and $\mathrm{M}$ phases $(G 2+M)$ over the same interval. 
A

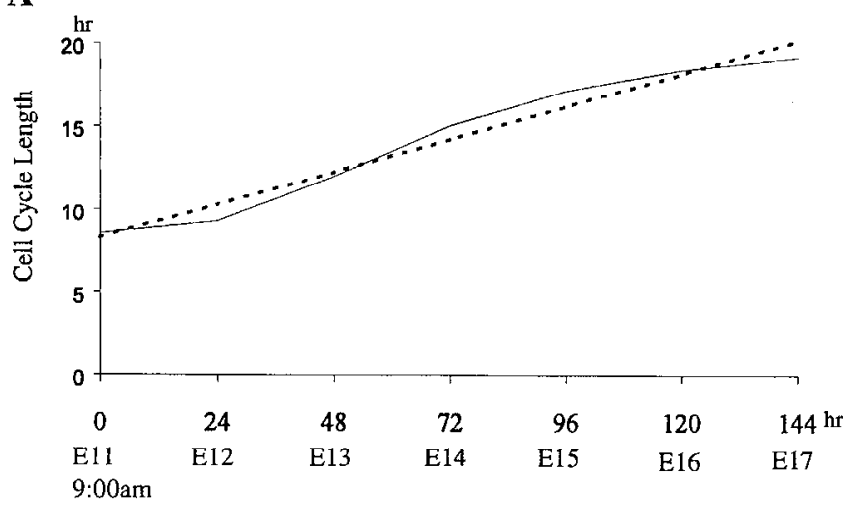

B

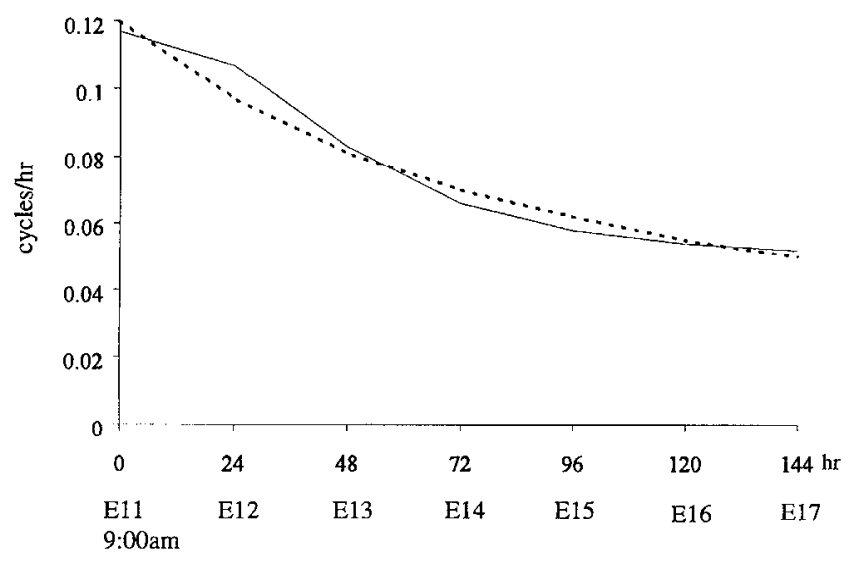

C

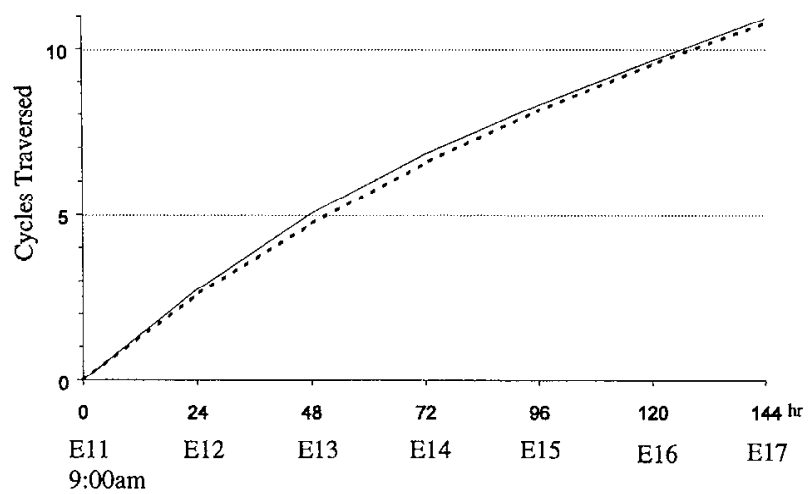

Figure 7. Cell cycle parameters plotted as continuous functions of time elapsed in hours or of the corresponding embryonic day $\mathbf{E} 11-\mathrm{E} 17$. The function is represented as a broken line where based upon a linear model of parameter progression but as a continuous line where based upon a sigmoidal model. The functions represented by the individual plots are the length of the cell cycle in $A$; the rate in cycles/hr that the cytogenetic epoch is heing traversed in $B$ and the cumulative integer cycles traversed in $C$. The values for E17 (144 hr) are extrapolated.

of multiple heterogeneous lineages, $T_{C}$ and $T_{G}$, will be the same. This means that $T_{G l}$, and therefore $T_{C}$, are not likely to be sufficient to distinguish the classes of cells being formed in the PVE at any given moment, and it follows, therefore, that it is doubtful that these parameters are predictors of cell class or, indeed, that those mechanisms which determine cell class di-
$\mathbf{A}$

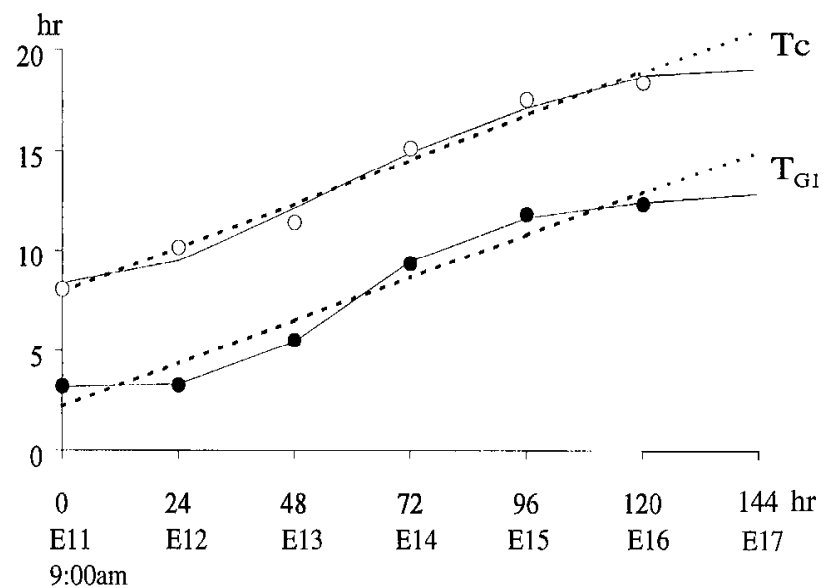

B

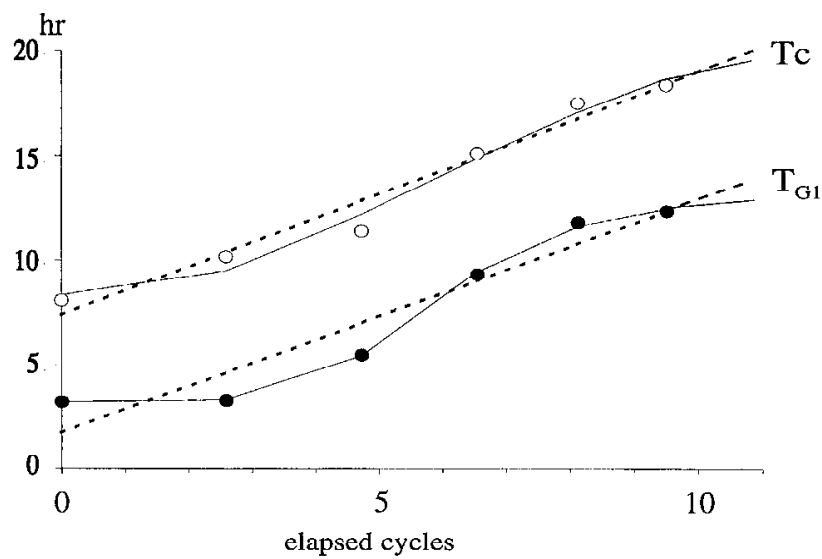

Figure 8. Progression in the length of the cell cycle $\left(T_{C}\right)$ and of the G1 phase $\left(T_{C I}\right)$ plotted as functions of clapsed timc $(A)$ and the scquencc of integer cell cycles $(B)$. The function is represented as a broken line where based upon a linear model of parameter progression but as a continuous line where based upon a sigmoidal model. Values for $T_{C}(\mathrm{O})$ and $T_{G l}(\mathbf{)})$ obtained by the experiments are also plotted. The two curves advance in parallel in both plots because the increase in $T_{G I}$ is apparently the determinant of the increase in $T_{C}$. The plot as a function of integer cycles $(B)$ is the more informative with respect to the proliferative process itself because the duration of the cell cycle is the denominator for the rate of cell production as this changes through the complete sequence of cycles. In both plots a sigmoidal model (i.e., a nonlinear function) provides the better fit implying that the rate of advance of $T_{C}$ and $T_{G l}$ is not determined in a direct linear way by either a direct timing or an integer cycle clocking mechanism.

rectly effect $T_{C, I}$. If not directly correlated with class, might variations in this parameter be correlated with and involved in the rate of cell production? The $Q$ fraction, rather than $T_{G /}$, is the principal determinant of the rate of neuronal formation and the total number of cells eventually formed in the PVE (Takahashi et al., 1994). Might $Q$ vary in some systematic way as the cytogenetic epoch proceeds? If so, might this pattern of variation correlate directly with the progression of $T_{G}$, observed here? Analyses in progress suggest that values of $T_{G I}$ and $Q$ do in fact covary and may be interdependent as the period of neocortical cytogenesis advances (Miyama et al., 1993, unpublished observations). It is apparent, for example that values of $Q$ in both the PVE (Takahashi et al., 1994) and SPP (Takahashi et al., 1995) are less than 0.5 on E14. On E14 the value of $T_{G I}$ is probably 
approximately the same in the two populations, and the rate of neuronal output as well as $T_{c i t}$ are comparably low in the two overlapping but greatly different proliferative populations (Takahashi et al., 1995). $T_{G,}$ for the PVE, and with it the value of $Q$ for this population, advance rapidly beyond E14 (this article and Takahashi et al., unpublished obsrvations) whereas the values of $T_{G /}$ and $Q$ for the SPP do not change significantly over the following 48 hr (Takahashi et al., 1995). More observations (in progress) will be required to establish the validity of this correlation which may be critical to our understanding of the developmental regulation of cell number arising from the cerebral PVE and, indeed, other proliferative populations in the embryo.

\section{References}

Altman J, Bayer SA (1990) Vertical compartmentation and cellular transformations in the germinal matrices of the embryonic rat cerebral cortex. Exp Neurol 107:23-35.

Atlas M, Bond VP (1965) The cell generation cycle of the eleven-day mouse embryo. J Cell Biol 26:19-24.

Bayer SA, Altman J (1991) Neocortical development. New York: Raven.

Berry M, Rogers AW (1965) The migration of neuroblasts in the developing cerebral cortex. J Anat 99:691-701.

Bisconte J-C, Marty R (1975) Etude quantitative du marquage radioautographique dans le systeme nerveux du rat. II. Caracteristiques finales dans le cerveau de l'animal adulte. Exp Brain Res 22:37-56.

Boulder Committee (1970) Embryonic vertebrate nervous system: revised terminology. Anat Rec 166:257-262.

Cajal S Ramon y (1952) Histologie du système nerveux de l'homme et des vértébrés. Madrid: Consejo Sup Invest Cient.

Caviness VS Jr (1982) Neocortical histogenesis in normal and reeler mice: a developmental study based upon $\left[{ }^{3} \mathrm{H}\right]$ thymidine autoradiography. Dev Brain Res 4:293-302.

Caviness VS Jr, Sidman RL (1973) Time of origin of corresponding cell classes in the cerebral cortex of normal and reeler mutant mice: an autoradiographic analysis. J Comp Neurol 148:14l-152.

Caviness VS Jr, Takahashi T, Nowakowski RS, Tsai L (1994) Regulated and nonregulated parameters of neocortical cytogenesis. In: Structural and functional organization of the ncocortcx (Albowitz B, Albus K, Kuhnt U, Nothdurft H-C, Wahle P, eds), pp 8-22. Berlin: Springer.

Fernandez V, Bravo H (1974) Autoradiographic study of the cerebral cortex in the rabbit. Brain Behav Evol 9:317-332.

Fujita S (1963) The matrix cell and cytogenesis in the developing central nervous system. J Comp Neurol 120:37-42.

Hall PA, Watt FM (1989) Stem cells: the generation and maintenance of cellular diversity. Development 106:619-633.

Hicks SP, D'Amato CJ (1968) Cell migration to the isocortex in the rat. Anat $\operatorname{Rec} 160: 619-634$.

Hinds JW, Ruffett TL (1971) Cell proliferation in the neural tube: an electron microscopic and Golgi analysis in the mouse cerebral vesicle. Z Zellforsch 115:226-264.

His W (1889) Die Neuroblasten und deren Entstehung im embryonalen Mark. Abh Math Phys Cl, Kgl Saechs Ges Wiss 15:313-372.

Hoshino K, Matsuzawa T, Murakami U (1973) Characteristics of the cell cycle of matrix cells in the mouse embryo during histogenesis of telencephalon. Exp Cell Res 77:89-94.

Hunt T (1991) Cell biology. Cell cycle gets more cyclins. Nature 350: $462-463$.

Jones EG (1984) History of cortical cytology. In: Cerebral cortex, Cellular components of the cerebral cortex (Peters A, Jones EG, eds), pp 1-32. New York: Plenum.

Kauffman SL (1966) An autoradiographic study of the generation cycle in the ten-day mouse embryo neural tube. Exp Cell Res 42:67-73.

LeVine SM, Goldman JE (1988) Embryonic divergence of oligodendrocyte and astrocyte lineages in developing rat cerebrum. J Neurosci $8: 3992-4006$.

Levinson SW, Goldman JE (1993) Both oligodendrocytes and astrocytes develop from progenitors in the subventricular zone of the postnatal rat forebrain. Neuron 10:201-212.

Levitt P, Cooper ML, Rakic P (1981) Coexistence of neuronal and glial precursor cells in the cerebral ventricular zone of the fetal monkey: an ultrastructural immunoperoxidase analysis. J Neurosci 1:27-39.

Lorente de No R (1938) Cerebral cortex: architecture, intracortical connections, motor projections. In: Physiology of the nervous system (Fulton JF, eds), pp 274-313. London: Oxford UP.

Luskin MB, Shatz CJ (1985) Neurogenesis of the cat's primary visual cortex. J Comp Neurol 242:611-631.

Mares V, Bruckner G (1978) Postnatal formation of non-neuronal cells in the rat occipital cerebrum: an autoradiographic study of the time and space pattern of cell division. J Comp Neurol 177:519-528.

Matsushime H, Ewen ME, Strom DK, Y KJ, Hanks SK, Rousssel MF, Sherr C.T (1992) Identification and properties of an atypical catalytic subunit (p34 psk-j3/cdk-4) for mammalian D type Gl cyclins. Cel! 71:323-334.

Millcr MW (1986) The migration and neurochemical differentiation of gamma-aminobutyric acid (GABA)-immunoreactive neurons in rat visual cortex as demonstrated by a combined immunocytochemicalautoradiographic technique. Brain Res 393:4l-46.

Mione MC, Danevic C, Boardman P, Harris B, Parnavelas JG (1994) Lineage analysis reveals neurotransmitter (GABA or glutamate) but not calcium-binding protein homogeneity in clonally related cortical neurons. J Neurosci 14:107-123.

Misson J-P, Edwards MA, Yamamoto M, Caviness VC Jr (1988) Mitotic cycling of radial glial cells of the fetal murine cerebral wall: a combined autographic and immunohistochemical study. Dev Brain Res 38:183-190.

Misson J-P, Takahashi T, Caviness VS Jr (1991) Ontogeny of radial and other astroglial cells in murine cerebral cortex. Glia 4:138-148.

Miyama S, Takahashi T, Caviness VS Jr (1993) Regional variation in cell cycle kinetics in the developing neocortex. Soc Neurosci Abst 19:29.

Nowakowski RS, Lewin SB, Miller MW (1989) Bromodeoxyuridine immunohistochemical determination of the lengths of the cell cycle and the DNA-synthetic phase for an anatomically defined population. J Neurocytol 18:311-318.

Patterson JA, Privat A, Ling EA, Leblond CP (1973) Investigation of glial cells in semithin sections. III. Transformation of subependymal cells in glial cells, as shown by radioautography after ${ }^{3} \mathrm{H}$-thymidine injection into the lateral ventricle of the brain of young rats. J Comp Neurol 149:83-102.

Potten CS, Lajtha LG (1982) Stem cells versus stem lines. Ann NY Acad Sci 397:49-61.

Potten SC, Loeffler M (1990) Stem cells: attributes, cycles, spirals, pitfalls and uncertainties. Lessons for and from the crypt. Development 110:1001 1020.

Privat A (1975) Postnatal gliogenesis in the mammalian brain. Int Rev Cytol 40:281-323.

Rakic P (1974) Neurons in rhesus monkey visual cortex: systematic relation between time of origin and eventual disposition. Science 183: 425-427.

Richardson HE, O'Keefe LV, Reed SI, Saint R (1993) A drosophila G1-specific cyclin $E$ homolog exhibits different modes of expression during embryogenesis. Development 119:673-690.

Sauer FC (1935) Mitosis in the neural tube. J Comp Neurol 62:377405.

Sauer ME, Walker BE (1959) Radioautographic study of interkinctic nuclear migration in the neural tube. Proc Soc Ext Biol 101:557-560.

Schaper A (1897) Die fruhesten Differenzierungsvorgange im Centralnervensystem. Arch Entwicklungsmech Organ 5:81-132.

Schutz A, Palm G (1989) Density of neurons and synapses in the cerebral cortex of the mouse. J Comp Neurol 286:442-455.

Schultz B, Nowak B, Maurer W (1974) Cycle times of the neural epithelial cells of various types of neuron in the rat. An autoradiographic study. J Comp Neurol 158:207-218.

Sherr CJ (1993) Mammalian G1 cyclins. Cell 73:1059-1065.

Shimada M, Langman J (1970) Cell proliferation, migration and differentiation in the cerebral cortex of the golden hamster. J Comp Neurol 139:227-244.

Shoukimas GM, Hinds JW (1978) The development of the cerebral cortex in the embryonic mouse: an electron microscopic serial section analysis. J Comp Neurol 179:795-830.

Sidman RL, Rakic P (1973) Neuronal migration, with special reference to developing human brain: a review. Brain Res $62: 1-35$.

Sidman RL, Rakic P (1982) Development of the human central nervous 
system. In: Histology and histopathology of the nervous system (Haymaker W, Adams RD, eds), pp 3-145. Springfield: Thomas.

Sidman RL, Miale IL, Feder N (1959) Cell proliferation and migration in the primitive ependymal zone: an autoradiographic study of histogenesis in the nervous system. Exp Neurol 1:322-333.

Smart I (1961) The subependymal layer of the mouse brain and its cell production as shown by autoradiography aftcr thymidinc-H3 injcction. J Comp Neurol 116:325-347.

Smart I, Leblond CP (1961) Evidence for division and transformation of neuroglia cells in the mouse brain, as derived from radioautography after injection of thymidine-H3. J Comp Neurol 116:349-367.

Stensaas LJ (1967) The development of hippocampal and dorsolateral pallial regions of the cerebral hemisphere in fetal rabbits. III. Twentynine millimeter stage, marginal lamina. J Comp Neurol 130:149-162.

Takahashi T, Nowakowski RS, Caviness VS Jr (1992) BUdR as an S-phase marker for quantitative studies of cytokinetic behaviour in the murine cerebral ventricular zone. J Neurocytol 21:185-197.
Takahashi T, Nowakowski RS, Caviness VS Jr (1993) Cell cycle parameters and patterns of nuclear movement in the neocortical proliferative zone of the fetal mouse. J Neurosci 13:820-833.

Takahashi T, Nowakowski RS, Caviness VS Jr (1994) Mode of cell proliferation in the developing mouse neocortex. Proc Natl Acad Sci USA 91:375-379.

Takahashi T, Nowakowski RS, Caviness VS Ir (1995) Farly ontogeny of the secondary proliferative population of the embryonic murine cerebral wall. J Neurosci 15:6058-6068

Tsai L-H, Takahashi T, Caviness VS Jr, Harlow E (1993) Activity and expression pattern of cyclin-dependent kinase 5 in the embryonic mouse nervous system. Development 119:1029-1040.

Tsai L-H, Delalle I, Caviness, VS Jr, Chae T, Harlow E (1994) p35, a neural specific regulatory subunit of the cdk5 kinase. Nature 371 : 419-423.

Waechter RV, Jaensch B (1972) Generation times of the matrix cells during embryonic brain development: an autoradiographic study in rats. Brain Res 46:235-250. 